\title{
Letter
}

\section{Projection of Diabetes Prevalence in Korean Adults for the Year 2030 Using Risk Factors Identified from National Data (Diabetes Metab J 2019;43:90-6)}

\author{
Bo Kyung Koo \\ Department of Internal Medicine, Seoul Metropolitan Government Seoul National University Boramae Medical Center, Seoul National University College of \\ Medicine, Seoul, Korea
}

Using sex-specific forecasting models, Baik [1] expected the future prevalence of diabetes mellitus to be $29.2 \%$ in men and $19.7 \%$ in women in 2030 among the Korean population, which is surprisingly high considering the previous report from International Diabetes Federation (IDF) [2]. Even though Korea is one of the most rapidly aging countries and the elderly population $\geq 65$ years old would increase by 2.3 times by 2030 compared with that of 2010 [3], the estimated prevalence may be too high considering that the number of Koreans aged $\geq 65$ years is projected to be $24.3 \%$ in 2030 [3] and that the prevalence of diabetes in the 60 s and $\geq 70$ s was $25.2 \%$ and $27.6 \%$, respectively, in 2013 Korean National Health and Nutrition Examination Survey (KNHANES) [4,5]. The prevalence of diabetes increases with age and reaches the peak by the $60 \mathrm{~s}$ and $70 \mathrm{~s}$; this was reported not only in the Korean population $[6,7]$ but also worldwide [8]. IDF reported the group aged 65 to 79 years shows the highest diabetes prevalence in both women and men, which was about $18 \%$ to $20 \%$ [8]. The plateau of the prevalence of diabetes according to age in those $>70$ s should be considered in the estimation of future diabetes prevalence in Korea.

Increasing prevalence of diabetes worldwide during the last decade might be not only from the increasing number of aging population but also from an increase in age-specific prevalence of diabetes [8]. In Korean adults, there have been changes in the gender- and age-specific prevalence of diabetes during the last decade; the prevalence of diabetes in the elderly population increased significantly, while this prevalence did not change significantly in young adults, especially in young women [5]. In addition, the contribution of each diabetic risk factor, such as obesity, $\beta$-cell dysfunction, sarcopenia, and socioeconomic status, in developing diabetes is also different according to gender, age, and survey year [9-11]. Furthermore, there was a disparity in the trends of the prevalence of obesity according to sex and age in the Korean population [12]; in the case of young women (aged 20 to 59 years), the prevalence of obesity was decreased during the last decade [12], whereas women aged $\geq 60$ years or men aged $<60$ years and $\geq 60$ years showed an increasing prevalence of obesity during the same period [12]. Overall, it might be better to estimate the projection of diabetes prevalence separately in those aged 30 to 59 years and $\geq 60$ years (or 30 to 64 years vs. $\geq 65$ years).

The future prevalence of diabetes might be determined by both the number of aging population and the trend of age-specific prevalence of diabetes [8]. If we can separate the trend of both factors in the estimation of projection of diabetes prevalence, more efficient public health plans can be prepared for future diabetes epidemics.

\section{CONFLICTS OF INTEREST}

No potential conflict of interest relevant to this article was reported.
Corresponding author: Bo Kyung Koo (D) https://orcid.org/0000-0002-6489-2656 Department of Internal Medicine, Seoul Metropolitan Government Seoul National University Boramae Medical Center, Seoul National University College of Medicine, 20 Boramae-ro 5-gil, Dongjak-gu, Seoul 07061, Korea

E-mail: bokyungkoomd@gmail.com
This is an Open Access article distributed under the terms of the Creative Commons Attribution Non-Commercial License (http://creativecommons.org/licenses/by-nc/4.0/) which permits unrestricted non-commercial use, distribution, and reproduction in any medium, provided the original work is properly cited. 


\section{REFERENCES}

1. Baik I. Projection of diabetes prevalence in Korean adults for the year 2030 using risk factors identified from national data. Diabetes Metab J 2019;43:90-6.

2. Whiting DR, Guariguata L, Weil C, Shaw J. IDF diabetes atlas: global estimates of the prevalence of diabetes for 2011 and 2030. Diabetes Res Clin Pract 2011;94:311-21.

3. Statistics Korea: Population Projections for Korea: 2010-2060. Available from: http://kostat.go.kr/portal/eng/pressReleases/8/8/index.board (updated 2011 Dec 7).

4. Noh J. The diabetes epidemic in Korea. Endocrinol Metab (Seoul) 2016;31:349-53.

5. Koo BK, Moon MK. Are we in the same risk of diabetes mellitus? Gender- and age-specific epidemiology of diabetes in 2001 to 2014 in the Korean population. Diabetes Metab J 2016;40: 175-81.

6. Won JC, Lee JH, Kim JH, Kang ES, Won KC, Kim DJ, Lee MK. Diabetes fact sheet in Korea, 2016: an appraisal of current status. Diabetes Metab J 2018;42:415-24.

7. Koo BK, Lee CH, Yang BR, Hwang SS, Choi NK. The incidence and prevalence of diabetes mellitus and related atherosclerotic complications in Korea: a National Health Insurance Database Study. PLoS One 2014;9:e110650.

8. International Diabetes Federation. IDF diabetes atlas. 8th ed. Brussels: IDF; 2017.

9. Koo BK, Roh E, Yang YS, Moon MK. Difference between old and young adults in contribution of $\beta$-cell function and sarcopenia in developing diabetes mellitus. J Diabetes Investig 2016; 7:233-40.

10. Koo BK, Kim SW, Yi KH, Park KS, Moon MK. Changing relative contribution of abdominal obesity and a family history of diabetes on prevalence of diabetes mellitus in Korean men and women aged 30-49 years from 2001 to 2010. J Diabetes 2015;7: 465-72.

11. Koo BK, Kim SW, Yi KH, Moon MK. Low economic status is identified as an emerging risk factor for diabetes mellitus in Korean men aged 30 to 59 years in Korean National Health and Nutrition Examination Survey 2008 to 2010. Diabetes Metab J 2015;39:137-46.

12. Shin HY, Kang HT. Recent trends in the prevalence of underweight, overweight, and obesity in Korean adults: the Korean National Health and Nutrition Examination Survey from 1998 to 2014. J Epidemiol 2017;27:413-9. 